\section{Aggressiveness and learning ability: Effect of histories of wins or defeats on avoidance learning in mice*}

\author{
GERALD A. HUDGENS and DONALD A. MacNEIL $\dagger$ \\ Behavioral Research Laboratory, U.S. Army Human Engineering Laboratories \\ Aberdeen Proving Ground, Md. 21005
}

Thirty-two mice, exposed to a series of fighting matches designed to elicit aggressive behavior, tended to become either dominant or submissive. When later trained on an avoidance task, submissive Ss learned significantly faster than dominant Ss. These results lend support to the hypothesis that the tendency for a dominant animal to respond with aggressiveness is maladaptive and leads to slower learning, whereas the tendency for a submissive animal to escape or avoid is adaptive and leads to faster learning.

In recent work on rhesus monkeys, Levine \& Gordon (1968) found a negative correlation between position in an observed dominance hierarchy and speed of learning on a modified Sidman avoidance task. Furthermore, a positive correlation between dominance position and adrenal cortical output of cortisol indicated that the dominant monkeys were more stressed during acquisition of the avoidance task. On the basis of these results, the investigators hypothesized that through a history of wins or defeats, dominant animals are reinforced for aggressiveness and submissive animals are reinforced for escape or avoidance responses. Thus, when a dominant animal is faced with an unnatural and threatening laboratory situation (e.g., an avoidance task), his tendency to respond with aggressiveness is maladaptive, leading to higher emotionality and slower learning. But when a submissive animal is faced with the same situation, his tendency to escape or avoid is adaptive, leading to lower emotionality and faster learning.

Levine and Gordon, however, had no knowledge of the monkeys' histories prior to their purchase as adults, and therefore, were unable to correlate their findings directly with the animals' past experience. Thus the present two studies were designed to examine more closely the relationship between an animal's history of wins or defeats and his speed of learning. Specifically, aggressive behavior was elicited by staging fighting matches with mice. Exposure to extended series of wins or defeats led to the development of

*In conducting the research described, the investigators adhered to the Guide for Laboratory Animal Facilities and Care as established by the Committee on the Guide for Laboratory Animal Resources, National Academy of Sciences, National Research Council

†Current address: Department of Pharmacology, Hoffman-LaRoche, Inc., Nutley, N.J. 07110. groups of dominant mice and groups of submissive mice that were later required to learn an avoidance task. According to Levine and Gordon's hypothesis, it was predicted that the submissive animals would learn faster than the dominant animals.

\section{EXPERIMENT 1}

Subjects

Twenty-four C57B 1/10J male mice from the Jackson Laboratories, Bar Harbor, Maine, were obtained at approximately 60 days of age. Ss were isolated for 4 weeks in individual stainless-steel suspended cages $\left(71 \frac{1}{2} \times 11 \times 8 \frac{1}{4} \mathrm{in}\right.$. $)$ and were maintained on food and water ad lib. Aggressive Training

The 24 Ss were divided into three equal groups. Half of the Ss in a group were randomly designated "hosts," and the other half were randomly designated "visitors." Within a group, hosts were paired with each of the four visitors, one a day. Thus, each host was paired with each visitor three times during the first 12 days of training.

To stage a match, the host's cage was partially opened, a visitor mouse was removed by the tail from his cage and placed into the host's cage, and the open portion of the cage was covered with clear Plexiglas to allow observation. The pair remained together for $10 \mathrm{~min}$, and $E$ recorded brief notes describing the match. Typical comments were: $A$ attacked $B$; $A$ chased B; B avoided A (i.e., A neither attacked nor chased B, but as A moved about the cage, $B$ maintained a respectable distance); nothing (neither A nor B showed any aggressiveness).

On the basis of the foregoing observations, the nine most aggressive Ss and the nine most submissive Ss were chosen to receive 16 days more of aggression training. One of the aggressive $\mathrm{Ss}$ that was chosen had been a visitor that had attacked even the more aggressive hosts. In subsequent matches, this $S$ always served as host to the same submissive $S$. The other eight aggressive Ss served as hosts to the other submissive Ss. Specifically, each host was paired with each visitor twice during the remaining training sessions. E continued to make notes on the fighting matches. Two days elapsed between the end of aggression training and the start of avoidance training.

\section{Apparatus}

Avoidance training took place in a black wooden box $\left(6 \times 16 \times 5 \frac{1}{2}\right.$ in.). A partition with a $1 \times 1$ in. opening divided the box in half, a piece of clear Plexiglas covered the top, and a $3 \cdot \mathrm{W}$ light (CS) was centered $4 \frac{1}{2}$ in. above the floor in each end of the box. The shock grids in each side were hinged at the middle of the box and were supported by microswitches and counterweights at the ends. Scrambled shock (UCS) was delivered to the grids from a matched impedance, AC shock source. The two intensities used were $0.3 \mathrm{~mA}$ (low) and $0.6 \mathrm{~mA}$ (high).

The avoidance program was controlled by standard timing and relay equipment. The CS was automatically presented in whichever side of the box $S$ happened to be at the start of the trial. Movement through the opening in the partition during the CS interval terminated the trial and was counted as an avoidance response. Movement to the opposite side of the box after the onset of shock also terminated the trial but was counted as an escape response. If movement did not occur within $15 \mathrm{sec}$ after shock onset, the trial was automatically terminated.

\section{Avoidance Training}

For three sessions prior to training, each $\mathrm{S}$ was placed in the avoidance apparatus and given a 10-min exposure to the program (no shock). Thereafter, every training session began with a 5-min adaptation period. On Day 1 of training, the first 15 trials consisted of a 1-sec presentation of the CS and a 10-sec presentation of the CS and UCS (low) simultaneously. The remaining five trials consisted of a 10-sec CS interval followed by a 15-sec CS-UCS (high) interval. On Day 2 the first five trials had a $1-\sec$ CS interval followed by a 15 -sec CS-UCS (low) interval. The remaining 15 trials had a $10-\mathrm{sec}$ CS interval followed by a $15-\mathrm{sec}$ CS-UCS (high) interval. Training trials on subsequent days consisted of a 10-sec CS interval followed by a 15 -sec CS-UCS interval. The first five trials were with low shock and the remaining 15 trials were with high shock. All trials were separated by a 30 -sec intertrial interval. Eighteen avoidance responses in a 20-trial session was established as the learning criterion. 


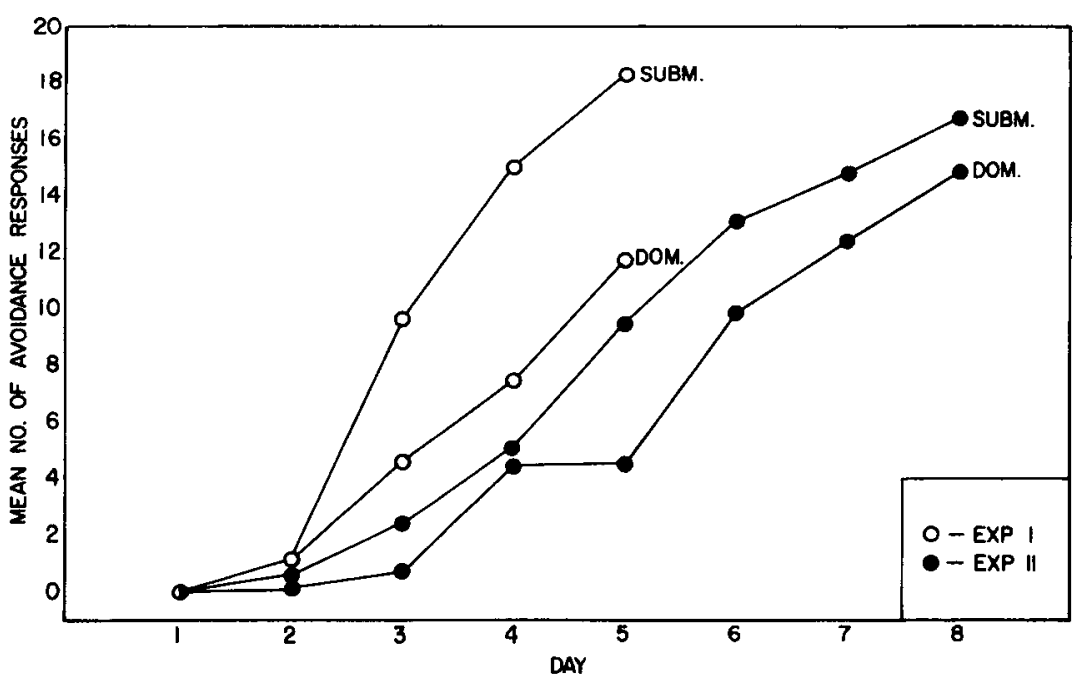

The experiment was terminated when all the $S s$ in one group reached criterion. Results

Over the 28 days of aggression training, the eight mice designated "dominant" displayed some form of aggression (attacking or chasing) on an average of 19.4 days $(\mathrm{SD}=7.2)$, whereas the eight mice designated "submissive" averaged only 0.2 days $(S D=0.6)$. The difference between the two means was highly significant $(\mathrm{t}=6.94, \mathrm{df}=14, \mathrm{p}<.01)$.

By Day 5 of avoidance training, seven out of eight submissive $S s$ and one dominant $S$ had reached criterion (Fig. 1). This difference in the number of Ss from each group that reached criterion is highly significant (Fisher exact probability, $\mathrm{p}=.005$ ). An analysis of variance was conducted on the avoidance scores for Days 2-5 only, since no $S$ in either group avoided on Day 1. The overall analysis yielded significant main effects due to aggression training $(\mathrm{F}=5.08, \mathrm{df}=1 / 13$, $\mathrm{p}<.05)$ and days of testing $(\mathrm{F}=43.86$, $\mathrm{df}=3 / 39, \quad \mathrm{p}<.01)$. A significant interaction between the training and testing factors was also obtained $(\mathrm{F}=4.27$, $\mathrm{df}=3 / 39, \mathrm{p}<.05)$. Subsequent tests for simple effects showed the submissive mice superior on Days 3,4 , and $5(F=3.72$, $\mathrm{df}=1 / 13, \quad \mathrm{p}<.10 ; \quad \mathrm{F}=7.88, \quad \mathrm{df}=1 / 13$, $\mathrm{p}<.05$; and $\mathrm{F}=18.44, \mathrm{df}=1 / 13, \mathrm{p}<.01$; respectively) but not superior on Day 2 $(\mathrm{F}=0.07, \mathrm{df}=1 / 13)$. No $\mathrm{S}$ avoided on Day 1. The one submissive $S$ that was always paired with the same aggressive $S$ took fewer days to reach criterion than did the aggressive $S$ (4 and 6 days, respectively). Because this pair of Ss was run only as a matter of curiosity during the second round of matches, their avoidance scores were not included in the statistical analyses.

\section{EXPERIMENT 2}

The aggression training procedure in
Fig. 1. Mean number of daily avoidance responses for Experiments 1 and 2.

the same way but was introduced into the host's side of the box where he remained for $6 \mathrm{~min}$. At the end of the session, the handling procedure was reversed in returning the visitor to his side of the box. In this way, the amount of handling was equivalent for both hosts and visitors.

The opposite procedure was used for training Pairs 8-13. Ss were randomly assigned to host and visitor roles and, for 3 weeks, matches were staged using the same handling procedure just described. During the last 3 weeks, Ss were exposed to each other in the total area of the box by raising the partition between the two sections. E recorded incidents of pursuits and/or attacks for each $S$ throughout aggression training.

\section{Avoidance Training}

The procedure was identical to that used in Experiment 1, except that training was extended to 8 days.

\section{Results}

Eight of the 13 pairs developed clear-cut dominant-submissive patterns and were chosen for avoidance training. Over the 30 days of aggression training, the eight dominant mice displayed aggressive behavior on an average of 14.0 days ( $\mathrm{SD}=4.61$ ), whereas the eight submissive mice averaged only 2.6 days $(\mathrm{SD}=2.7)$. The difference between the two means was highly significant $(t=5.61, d f=14$, $\mathrm{p}<.01)$. It should be noted that there appeared to be less agressive behavior demonstrated in this experiment than was observed in Experiment 1.

The results of avoidance training are shown in Fig. 1. Again, the dominant Ss took longer to learn than the submissive Ss, although overall, the Ss in Experiment 2 took longer to learn than did the $S s$ in Experiment 1. Preliminary examination of the avoidance data revealed a significant positive correlation between total avoidance scores for pair members (Pearson $\mathrm{r}=0.81$, df $=6, \mathrm{p}<.05$ ). Since the assumption of independent samples could not be met, the use of analysis of variance was precluded, and the sign test was chosen for testing the differences between dominant and submissive $S s$ in avoidance performance. Analysis of difference scores between pair members showed that the submissive Ss were significantly superior on Days 5,6 , and 7 (sign test, $\mathrm{p}=.035$ for Days 5 and 6 , and $\mathrm{p}=.062$ for Day 7).

\section{DISCUSSION}

In both Experiments 1 and 2, Ss with histories of defeats learned to avoid shock significantly faster than Ss with histories of 
tories. These findings lend support to Levine and Gordon's hypothesis and suggest that this inverse relationship between aggressiveness and avoidance learning ability may apply across species. The generality of these findings is also supported by the similarity of the findings from the two experiments where the rearing conditions and methods of programming in histories of wins and defeats were different.

Levine and Gordon reported that their dominant Ss spent the majority of their avoidance training time attacking the shock grid and other parts of their training cage. None of the mice in these studies were observed attacking any part of the avoidance apparatus during training. This may mean that no appropriate stimulus was present to elicit the attack response.

Thus far attention has been focused upon the maladaptive behavior of the dominant animals and not upon the adaptive behavior of the submissive animals. The obtained results could be explained, at least in part, in terms of the nonaggressive animal's having learned to seek alternate forms of behavior (other than attacking) when faced with a threatening or otherwise stressful situation.

At least one other possible explanation exists for our findings: that there exists an innate inverse correlation between learning ability and aggressiveness and that the aggressive Ss may have been poorer learners due to their genetic rather than their experiential histories. The procedures of Experiment 1, however, were established to minimize the chances of assigning Ss to groups according to innate aggressive tendencies. Ss to be dominant were randomly assigned to "host" roles and those to be submissive to "visitor" roles. Hosts remained in their own familiar "territory" when exposed to visitors. These procedures were successful to the extent that eight of the nine Ss that displayed aggression reliably throughout the initial round-robin pairings were those randomly assigned to the host roles. It is doubtful, however, that this problem can ever be resolved with complete certainty. While it may be possible to train an innately aggressive animal into submission (e.g., by restraining or dangling him while allowing another aggressive $S$ to attack him), there is no way of training an innately nonaggressive animal to be dominant. That is, there is no way short of CNS stimulation to be certain of ever eliciting an aggressive response from a truly nonaggressive animal. The innate inverse correlation argument is also in opposition to the position taken by Denenberg \& Bell (1959), who proposed that there should be a direct correlation between aggressiveness and learning ability since both are adaptive traits. They were able to demonstrate significant correlations between avoidance learning and certain social behaviors generally associated with aggression (latency to first contact with opponent and self-grooming) but not between learning and actual aggressive behaviors (they isolated their mice from weaning until adult testing as we did in Experiment 2, a condition that tends to minimize adult aggression: Hudgens, Denenberg, \& Zarrow, 1968). It is concluded that the present experiments demonstrate a significant negative relationship between aggressiveness and avoidance learning in C57B 1/10J mice and that, while the possibility of an innate correlation between these traits cannot be completely ruled out, the evidence strongly suggests that the established relationship is due to experiential factors.

It is quite obvious from Fig. 1 that the Ss in Experiment 2 took considerably longer to learn to avoid shock than did Ss in Experiment 1. Since the learning situation was the same in both cases, this difference would appear to relate to some aspect of the aggression training procedure. In Experiment 2 the dominant mice had lower aggression scores and the submissive mice had higher aggression scores than did those in Experiment 1. This suggests that mice in the second experiment did not develop as well-defined (aggressive) response patterns as had mice in the first experiment; and this uncertainty of response to an emotional or threatening situation could have been even more disruptive to avoidance learning than a history of repeated victories.

There was another difference in behavior between the $S s$ in the two experiments worthy of mention here. In Experiment 1, after the first few pairings, the host mice were almost invariably observed picking up their own tails and carrying them about the cage upon introduction of the visiting mouse and before any display of aggression toward the visitor. This behavior was not recorded, but it was common to all hosts and was quite persistent over the many test days. This apparent displaced aggression, however, was never observed in any of the Ss under any of the conditions of Experiment 2.

\section{REFERENCES}

DENENBERG, V. H., \& BELL, R. W. Relationships between social reactions and avoidance conditioning. Physiological Zoology, $1959,32,51-56$.

HUDGENS, G. A., DENENBERG, V. H., \& ZARROW, M. X. Mice reared with rats: Effects of preweaning and postweaning social interactions upon adult behavior. Behaviour, $1968,30,259-274$.

LEVINE, M. D., \& GORDON, T. P. Emotional response of rhesus monkeys to chronic psychological stress. Proceedings of the Army Science Conference, 1968, 2, 17-25.

\title{
Conditioning a one-trial passive-avoidance response to a visual or auditory $\mathrm{CS}$
}

\author{
RONALD P. GRUBER \\ Biophysics Laboratory, Edgewood Arsenal, Md. 21010
}

Conventional one-trial passive-avoidance-response (PAR) experiments have implied that it is in part a conditioned emotional response (CER) to situational cues, including visual cues. In this study, the development of a one-trial PAR to a visual CS was not possible, suggesting that one-trial training is not sufficient to develop a CER to visual cues. Using an auditory CS, however, a weak CR could be established after only one trial.

Recent experiments employing a one-trial passive-avoidance response (PAR) have suggested that it is a conditioned emotional response (CER) to situational cues as well as an instrumental response (Pinel, 1968; Spevack \& Suboski, 1967).
However, by using black-white conditioning boxes wherein the shock and safe sides are designated a particular color, it is implied that the cues are primarily visual. The importance of visual cues was emphasized by Randall \& Riccio (1969) 